\title{
Suppressive Action of Docosahexaenoic Acid Enriched-Euglena on Reduction of Endothelium-Dependent Relaxation in Stroke-Prone Spontaneously Hypertensive Rats (SHRSP)
}

\author{
Tetsuo Murakami, ${ }^{*}$ Hiroshi Ogawa, ${ }^{1}$ Masahiro Hayashi ${ }^{2}$ \\ and Hajime YoshizumI \\ Department of Food Science and Nutrition, Faculty of Agriculture, \\ Kinki University, Nara 631, Japan \\ ${ }^{1}$ Department of Hygiene, Kinki University School of Medicine, \\ Osaka 589, Japan \\ ${ }^{2}$ Department of Food Science and Technology, College of Horticulture, \\ Minami-Kyushu University, Miyazaki 884, Japan
}

(Received October 7, 1996)

Summary Stroke-prone spontaneously hypertensive rats (SHRSP) were fed a diet containing docosahexaenoic acid (DHA)-enriched Euglena glacilis (DHA-Euglena) as the protein source from 5 weeks of age. The effects on endothelial functions were investigated by perfusion experimentation using mesenteric vasculature, and compared with the effects of antihypertensive drugs. (1) At 13 weeks of age, SHRSP fed the DHA-Euglena diet showed an average blood pressure of $220 \mathrm{mmHg}$, which was $20 \mathrm{mmHg}$ lower $(p<0.05)$ than that in the control group, while SHRSP of the captopril-treated group (angiotensin I converting enzyme inhibitor: $200 \mathrm{mg} / \mathrm{L}$ drinking water) and hydralazine-treated group (vasodilator: $60 \mathrm{mg} / \mathrm{L}$ drinking water) showed marked hypotensive effects with blood pressures of $150-160 \mathrm{mmHg}$ and $180-190 \mathrm{mmHg}$, respectively. (2) The constriction response to norepinephrine (NE) was lower $(p<0.01)$ in the mesenteric vasculature isolated from the DHAEuglena-treated SHRSP than in that from the control group. (3) When the mesenteric vasculature isolated from 13-week-old SHRSP fed the DHA-Euglena diet was perfused with an acetylcholine solution $\left(10^{-6} \mathrm{M}\right)$ in the presence of $\mathrm{NE}\left(8 \times 10^{-6} \mathrm{M}\right)$, the relaxation rate was $81 \%$, which was higher $(p<0.01)$ than that in the control group (61\%). Among the antihypertensive-treated groups, the captopril-treated group gave nearly the same relaxation rate as the DHA-Euglena diet group, while the hydralazine-treated group indicated a slightly lower rate (65\%). At 18 weeks of age, the endothelium-dependent relaxation of SHRSP in the

* To whom correspondence should be addressed. 
control group was further reduced (28\%), but in both the DHA-Euglena diet group and antihypertensive-treated groups, the relaxation rates were not substantially different from the levels at 13 weeks of age. Reduction of the endothelium function in SHRSP occurs due to aging and blood pressure elevation. However, by improving nutritional conditions by the feeding of a DHA-Euglena diet, the endothelial functions were protected without a fall in blood pressure unlike antihypertensive drugs. It is hence considered that nutritional improvement helps maintain a sound architecture for the vascular wall, thereby leading to the suppression and delay of onset of cerebrovascular diseases, and subsequently to the prolongation of life-span.

Key Words docosahexaenoic acid, Euglena gracilis Z, SHRSP, captopril, hydralazine, endothelium-dependent relaxation, mesenteric artery, acetylcholine, norepinephrine

Ever since endothelium-dependent relaxation was discovered by Furchgott and Zawadzki (1), the importance of the physiological role of endothelial cells has been recognized. The endothelial cells produce substances which relax or contract the vascular smooth muscles, and are engaged in the regulation of blood pressure. It is believed that the endothelium-derived relaxing factor (EDRF) includes NO and prostaglandin $\mathrm{I}_{2}\left(\mathrm{PGI}_{2}\right)$, and that the endothelium-derived contracting factor (EDCF) includes endothelin, prostaglandin $\mathrm{H}_{2}\left(\mathrm{PGH}_{2}\right)$ and thromboxane $\mathrm{A}_{2}$, among others $(2,3)$. It has been recently suggested that the EDRF is related with the cause of hypertension or ischemic heart disease (4). In the blood vessels of spontaneously hypertensive rats (SHR) or stroke-prone SHR (SHRSP), the endothelium-dependent relaxation is weaker than in normotensive Wistar-Kyoto rats (WKY) (5-12), and hence relation to the maintenance of hypertension has been discussed. Impairment of the endothelial function increases with aging in SHRSP, but the degree of damage is reported to be dependent on the level of a rat's blood pressure or the duration of exposure to hypertension $(9,11)$. However, by suppressing the development of hypertension by administering an antihypertensive drug to SHRSP before blood pressure is elevated, impairment by endotheliumdependent relaxation of the aorta can be prevented $(9,11,12)$, and endotheliumdependent relaxation is recovered by lowering the blood pressure through the administration of an antihypertensive drug from the hypertensive stage (13). Therefore, it is understood that this impairment is not determined genetically, but is a secondary change due to the persistence of hypertension.

The authors previously reported that a diet containing Euglena cell as the protein source was effective to delay markedly the incidence timing of stroke lesion and prolong the life-span, although its suppressive action on elevating the blood pressure of SHRSP was not significant (14). In these rats, suppression of the decrease of elastin, an elastic protein composing the vascular wall, and suppression 
of hypertrophy of the vascular wall were observed, and it has been shown that a Euglena diet suppressed the aging of blood vessels. The authors recently conducted similar experiments using Euglena enriched with docosahexaenoic acid (DHA), and found that it had a stronger suppressive action on blood pressure elevation and on stroke lesion than Euglena by ordinary cultivation (15). In this paper, the effects of Euglena enriched with DHA on the functional impairment of endothelial cells induced by the elevation of blood pressure in SHRSP are studied, and compared with the actions of antihypertensive drugs.

\section{MATERIALS AND METHODS}

Materials. Euglena gracilis $\mathrm{Z}$ was a wild-type strain, and it was cultivated at $28^{\circ} \mathrm{C}$ in a medium composed of $2 \%$ glucose, $0.7 \%$ ammonium sulfate, $0.5 \%$ corn steep liquor, minerals and vitamins for $48 \mathrm{~h}$ in the dark. After the addition of $0.5 \%$ DHA ethyl ester, cultivation was continued for a further $24 \mathrm{~h}$. Cells were harvested, washed three times with distilled water and kept at $-20^{\circ} \mathrm{C}$ (DOCOSAEuglena; a commercial product of Harima Chemicals, Inc., Ibaraki, Japan). It was freeze-dried, and ground to powder form before use. The chemical components were $7.1 \%$ moisture, $44.0 \%$ crude protein, $22.7 \%$ crude fat, $3.2 \%$ crude ash and 23.0\% nitrogen-free extract. In the total lipid of the DOCOSA-Euglena, the composition of the main $n-3$ and $n-6$ fatty acids (16) was $4.36 \% \mathrm{C}_{20: 4}(n-6), 6.94 \%$ $\mathrm{C}_{20: 5}(n-3), 6.94 \% \mathrm{C}_{22: 5}(n-6)$ and $61.22 \% \mathrm{C}_{22: 6}(n-3)$.

Diet and drugs. The control diet used was a commercial powder diet (Funabashi SP, Funabashi Farm Co. Ltd., Chiba, Japan). The diet was composed of $7.0 \%$ moisture, $21.8 \%$ crude protein, $4.5 \%$ crude fat, $3.4 \%$ crude fiber, $5.7 \%$ crude ash and 57.6\% nitrogen-free extract. The dietary composition of the Euglena diet is shown in Table 1. Protein content in the Euglena diet was adjusted to 22\%, as in the control diet. The experimental diet (DHA-Euglena diet) was prepared by mixing $50 \%$ of the Euglena diet and $50 \%$ of the control diet. The antihypertensive

Table 1. Composition of Euglena diet.

\begin{tabular}{lr}
\hline \multicolumn{1}{c}{ Ingredients } & $(\%)$ \\
\hline Euglena cells -Corn starch & 50.05 \\
Vitamin mixture $^{1}$ & 36.71 \\
Salt mixture $^{1}$ & 1.00 \\
Cellulose powder $^{2}$ & 4.00 \\
Choline chloride & 3.00 \\
Soybean oil & 0.24 \\
\end{tabular}

The dietary protein content was adjusted to $22 \%$ as in the control diet (Funabashi SP).

${ }^{1}$ AIN-76 Prescription (CLEA Japan Ltd.).

${ }^{2}$ Avicer FD-101 (Asahi Chemical Industry Co. Ltd.). 
drugs used were hydralazine hydrochloride (Sigma Chemical Co., St Louis, MO, USA), as the peripheral vasodilator, and captopril (Sigma Chemical Co.), as the angiotensin I converting enzyme inhibitor. The other drugs used in this experiment included norepinephrine bitartrate (Sigma Chemical Co.) and acetylcholine chloride (Wako Pure Chemical Industries Ltd., Osaka, Japan).

Animals and feeding conditions. Male SHRSP ( $\mathrm{A}_{3}$ strain) and normotensive Wistar-Kyoto rats (WKY), bred in our laboratory, were used. SHRSP showed a relatively rapid elevation in blood pressure and shorter life-span. After feeding the control diet, the rats were divided into a control and experimental groups each consisting of 5 or 7 rats, at 5 weeks of age. The former group was fed the control diet (Funabashi SP) and the latter was further divided into a DHA-Euglena diet group and antihypertensive-treated groups. The DHA-Euglena diet group was fed a DHA-Euglena diet from 5 weeks of age. In experiments of antihypertensive treatment, the antihypertensive drugs were mixed with drinking water (captopril group: $200 \mathrm{mg}$ captopril/L drinking water; hydralazine group: $60 \mathrm{mg}$ hydralazine hydrochloride/L drinking water) and administered together with the control diet. Rats were raised in a room with temperature set at $23 \pm 1{ }^{\circ} \mathrm{C}$, humidity at $55 \pm 5 \%$ and a light/dark alternation of $12 \mathrm{~h}$ (lighted time from $07: 00$ to 19:00). The diet and drinking water were given ad libitum. During the experimental period, blood pressure and body weight were measured once a week. The blood pressure was measured without anesthesia by the tail-cuff method (model KN210-1, Natsume Co. Ltd., Tokyo, Japan). Rats were sacrificed and autopsied. Removed brains were fixed in $10 \%$ formalin and histologically examined for the presence or absence of cerebral stroke lesion.

Preparation of mesenteric vasculature. The animals were sacrificed by decapitation. Heparin (10 units/100 g, intravenously) was administered before death to reduce clotting in the fine resistance vessels of the mesentery. The abdomen was incised, the inferior mesenteric and superior pancreatico-duodenal arteries were ligated, the superior mesenteric artery was cannulated with a polyethylene catheter (PE 90; Becton Dickinson and Company, USA) and the entire mesentery was removed from the intestinal tract.

Experiment protocol for perfusion. The mesenteric vasculature isolated from SHRSP was wrapped in gauze moistened with Tyrode solution, placed in a $50 \mathrm{~mL}$ chamber $\left(37^{\circ} \mathrm{C}\right)$ and perfused through the cannula with Tyrode solution $\left(37^{\circ} \mathrm{C}\right)$ by a peristaltic pump (IWAKI RST-100, Iwaki Glass Co., Ltd.). The perfusate was aerated with a mixture of $95 \% \mathrm{O}_{2}: 5 \% \mathrm{CO}_{2}$, and its composition was as follows (in $\mathrm{mM}$ ): $\mathrm{NaCl}, 137 ; \mathrm{KCl}, 5.4 ; \mathrm{CaCl}_{2}, 22.0 ; \mathrm{NaHCO}_{3}, 11.9 ; \mathrm{NaH}_{2} \mathrm{PO}_{4}, 0.4$; glucose, 5.6; and $\mathrm{pH}$ 7.3. The perfusion speed was adjusted by the flow rate so as to keep the perfusion pressure in the pressure transducer (SEN-6102M: Nippon Koden, Japan) at $30 \mathrm{mmHg}$. To stabilize the perfusion pressure, Tyrode solution was perfused for $60 \mathrm{~min}$. Then by perfusing $80 \mathrm{mM}$ of $\mathrm{KCl}$, the reactivity of the mesenteric preparation was confirmed. The concentration of norepinephrine (NE) used for contraction of the mesenteric preparation was determined at $80 \%$ of maximum 


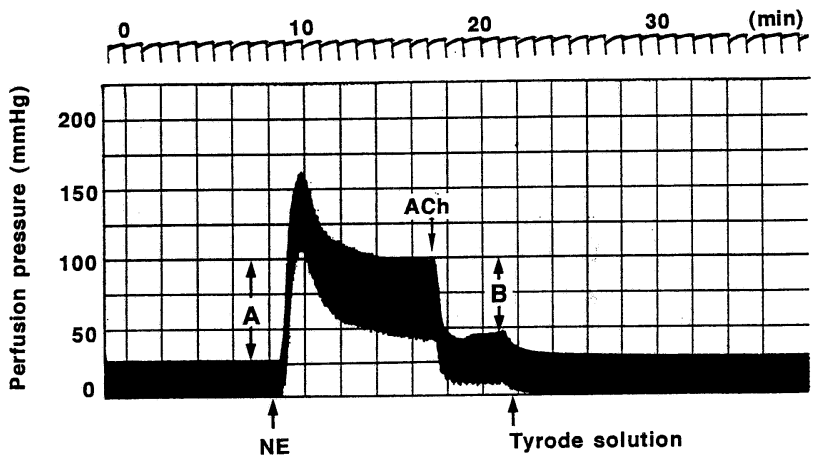

Fig. 1. Measurement of endothelium-dependent relaxation induced of acetylcholine in mesenteric vasculature by perpusion. Mesenteric vasculature was precontracted by the perfusion of norepinephrine (NE), and acetylcholine (ACh) was perfused in the presence of NE to induce endothelium-dependent relaxation when the contractions achieved steady state. The amplitude $A$ was contraction by $\mathrm{NE}$ and $B$ was relaxation by $\mathrm{ACh}$ in the presence of NE. Relaxation rate was determined as $B \mid A \times 100$.

contraction $\left(\mathrm{EC}_{80}\right)$ from the dose-response curve. The mesenteric preparation was precontracted at this concentration $\left(\mathrm{NE} ; 8 \times 10^{-6} \mathrm{M}\right)$, acetylcholine $\left(\mathrm{ACh} ; 10^{-6} \mathrm{M}\right.$ ) in the presence of $\mathrm{NE}\left(8 \times 10^{-6} \mathrm{M}\right)$ was perfused and the relaxative reaction was investigated. Pressure changes at this time were recorded (WI-681G; Nippon Koden). The relaxation rate was determined as $B / A \times 100$, where $A$ is the contraction height by NE and $B$ is the relaxation by $\mathrm{ACh}$ in the presence of $\mathrm{NE}$ (Fig. 1).

Statistical processing. Experimental data were shown as the M \pm SD. After the variance of values to be compared was assayed, the results were analyzed by Student's $t$-test or by Welch's $t$-test to determine the significant difference. The MUSCOT statistical analysis program (YUKMS Co., Tokyo, Japan) was used for the analysis, and $p<0.05$ was defined as being significant.

\section{RESULTS}

\section{Changes of blood pressure and body weight}

Figure 2 illustrates changes in the blood pressure (top panel) and body weight (bottom panel) of SHRSP fed the DHA-Euglena diet and treated with antihypertensive drugs from 5 weeks of age. The blood pressures in the control group were $210 \pm 7 \mathrm{mmHg}$ on average at 10 weeks of age, $236 \pm 8 \mathrm{mmHg}$ at 13 weeks of age and $236 \pm 4 \mathrm{mmHg}$ at 18 weeks of age. In the DHA-Euglena diet group, the elevation of blood pressure was suppressed from the initial stage of administration, and at 10 weeks of age, it was $20 \mathrm{mmHg}$ lower than the average pressure in the control group $(p<0.05)$. Thereafter, the blood pressure remained between 210 and 

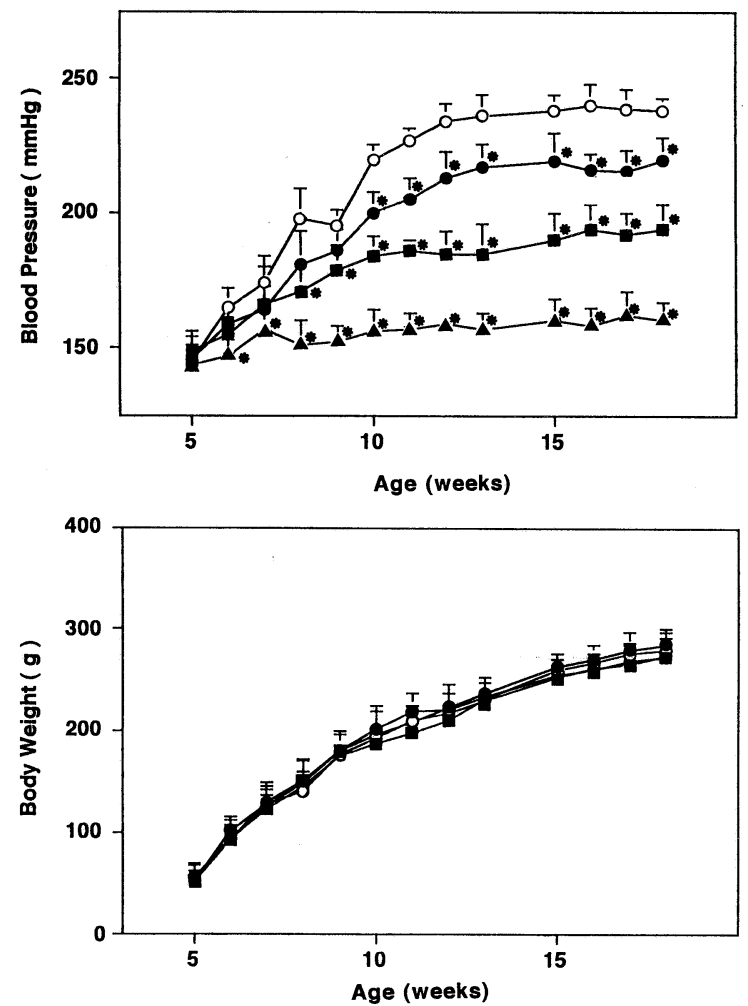

Fig. 2. Changes of blood pressure (upper panel) and body weight (bottom panel) in SHRSP fed DHA-Euglena diet and administered with antihypertensive drugs ( $200 \mathrm{mg}$ captopril/L drinking water; hydralazine $60 \mathrm{mg}$ hydralazine/L drinking water) from 5 weeks of age on blood pressure and body weight (bottom panel) in SHRSP. The values are expressed as the $\mathbf{M} \pm$ SD. Asterisks indicate significant difference from the control $(p<0.01)$. $\bigcirc$, control group $(n=12)$; $\bullet$, DHAEuglena diet group $(n=13)$; $\Delta$, captopril-treated group $(n=12)$; $\mathbf{\square}$, hydralazinetreated group $(n=12)$.

$220 \mathrm{mmHg}$. On the other hand, in the SHRSP treated with antihypertensive drugs, the elevation of blood pressure was suppressed markedly, ranging from 155 to 165 $\mathrm{mmHg}$ in the captopril-treated group and 180 to $200 \mathrm{mmHg}$ in the hydralazinetreated group. At 13 weeks of age, the blood pressure was $236 \pm 8 \mathrm{mmHg}$ in the control group, $220 \pm 5 \mathrm{mmHg}$ in the DHA-Euglena diet group, $155 \pm 5 \mathrm{mmHg}$ in the captopril-treated group, and $188 \pm 5 \mathrm{mmHg}$ in the hydralazine-treated group. The body weights of the DHA-Euglena diet group and antihypertensive-treated groups were similar to that of the control group.

Incidence rate of stroke lesion

Brains were removed from both rats that diet natural death and those which 
were sacrificed, and the presence or absence of stroke lesion was investigated. In the control group, the incidence rates of stroke in the groups sacrificed at 13 and 18 weeks of age were $60 \%$ and $100 \%$, respectively. In the DHA-Euglena diet group, in the animals sacrificed at 13 and 18 weeks of age, the incidence rate was $0 \%$. In both antihypertensive-treated groups, it was also $0 \%$.

Constriction responses to norepinephrine of mesenteric preparation isolated from SHRSP

Figure 3 shows the dose-response curve produced by the perfusion of NE in mesenteric vasculature isolated from SHRSP of 13 weeks of age. The perfusion pressure increased in a dose-dependent manner by NE. The contraction response to $\mathrm{NE}$ in the control group began from $10^{-7} \mathrm{M}$, and reached maximum contraction at $10^{-4} \mathrm{M}$. The NE contraction responses in the mesenteric vasculature of DHAEuglena diet group and captopril-treated group were small as compared to the control group, and the contraction response of the hydralazine-treated group was intermediate of them. The dose-response curve at 13 weeks of age in the control group is shown in Fig. 4. From this experiment, the concentration of NE for observing endothelium-dependent relaxation was determined at $8 \times 10^{-6} \mathrm{M}$, corresponding to $\mathrm{EC}_{80}$.

\section{Endothelium-dependent relaxation of mesenteric vasculature isolated from $W K Y$ and SHRSP}

The relaxation rate of the mesenteric vasculature by cumulative perfusion of

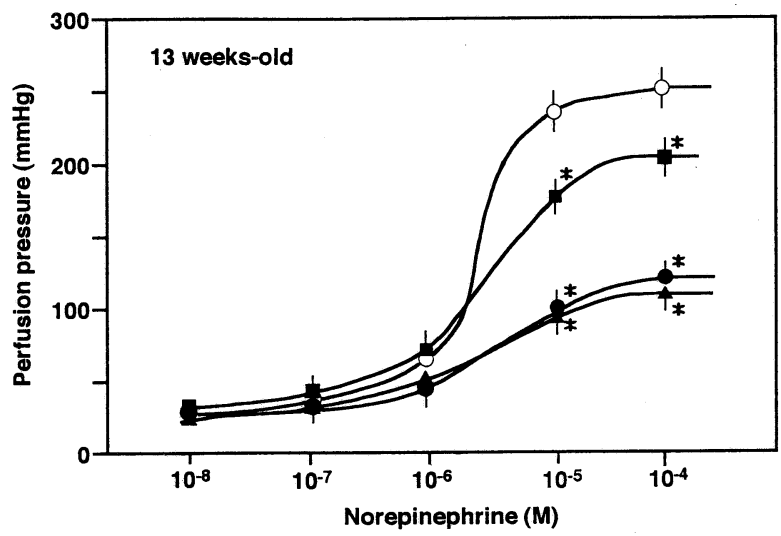

Fig. 3. Dose-response curves for contraction induced by the perfusion of norepinephrine in mesenteric vasculature from SHRSP fed DHA-Euglena diet and given antihypertensive drugs $(200 \mathrm{mg}$ captopril/L drinking water, $60 \mathrm{mg}$ hydralazine/L drinking water) for 8 weeks from 5 weeks of age. The values are expressed as the $\mathbf{M} \pm \mathrm{SD}$. Asterisks indicate significant difference from the control $(p<0.01)$. $\bigcirc$, control group $(n=6)$; $\bullet$, DHA-Euglena diet group $(n=5) ; \boldsymbol{\Delta}$, captopriltreated group $(n=5) ; \mathbf{\square}$, hydralazine-treated group $(n=5)$. 


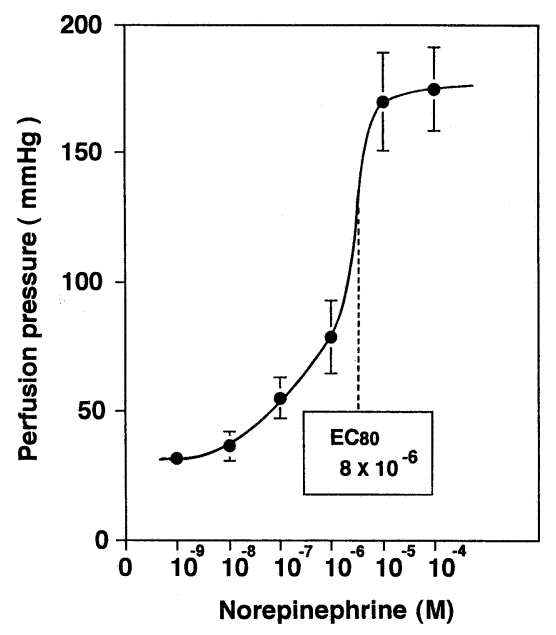

Fig. 4. Dose-response curve for contraction induced by the perfusion of norepinephrine in mesenteric vasculature from SHRSP. Male SHRSP of 13 weeks of age were used for this study. Each point represents $\mathbf{M} \pm \mathbf{S D}$ of 5 rats.
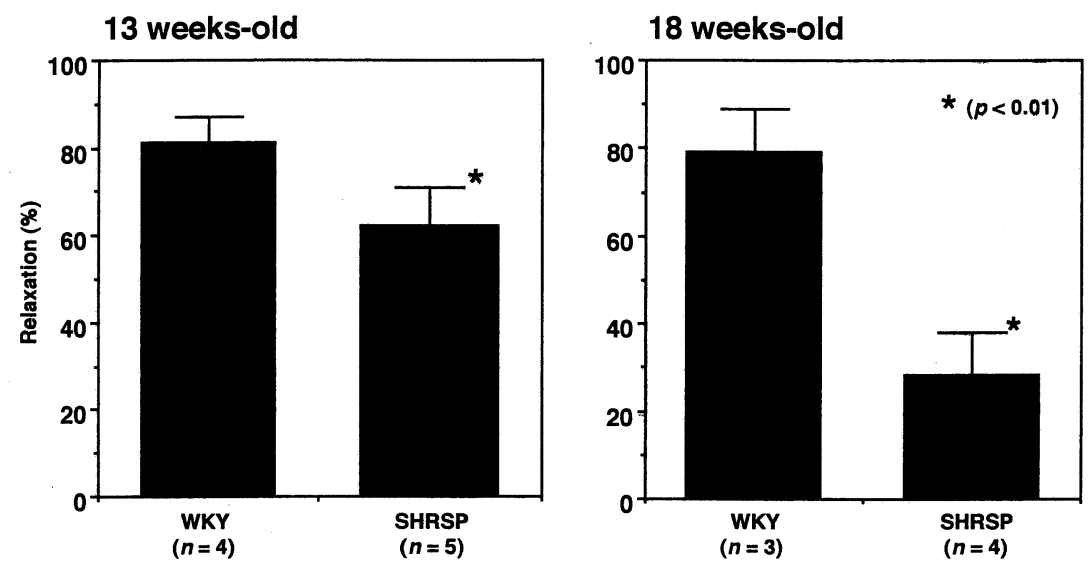

Fig. 5. Endothelium-dependent responses in mesenteric vasculature from WKY and SHRSP. Preparations of mesenteric vasculature were precontracted by $8 \times$ $10^{-6} \mathrm{M}$ norepinephrine (NE) and $10^{-6} \mathrm{M}$ acetylcholine (ACh) was perfused in the presence of NE. The values are expressed as $\mathbf{M} \pm \mathbf{S D}$.

ACh $\left(10^{-6} \mathrm{M}\right)$ in the presence of NE was $62 \pm 9 \%$ in 13-week-old SHRSP, which was significantly smaller as compared to the rate in WKY (Fig. 5). At 18 weeks of age, the relaxation rate dropped to $28 \pm 10 \%$ in SHRSP but was almost unchanged in WKY. 

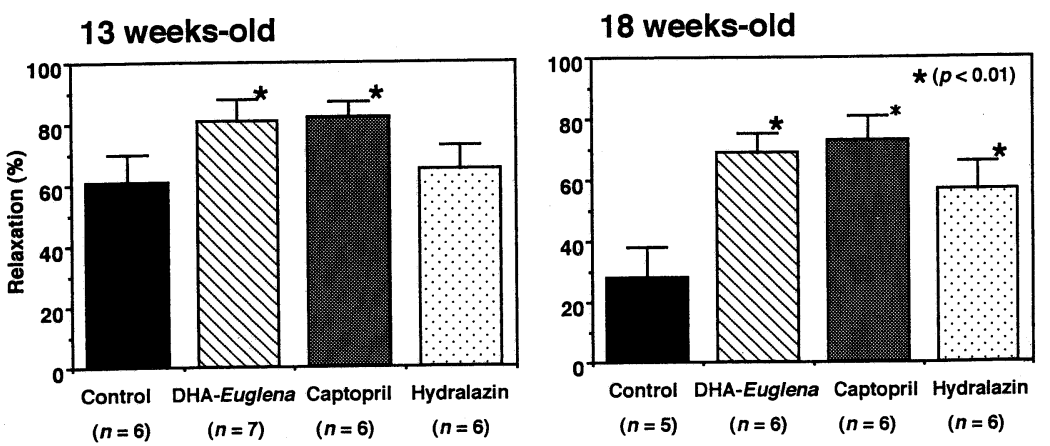

Fig. 6. Endothelium-dependent responses in mesenteric vasculature from SHRSP fed DHA-Euglena diet and administered with antihypertensive drugs. Preparations of mesenteric vasculature were precontracted by $8 \times 10^{-6} \mathrm{M}$ norepinephrine (NE) and $10^{-6} \mathrm{M}$ acetylcholine (ACh) was perfused in the presence of NE. The values are expressed as $\mathbf{M} \pm \mathbf{S D}$.

Endothelium-dependent relaxation of mesenteric vasculature in SHRSP fed DHAEuglena diet or treated with antihypertensive drugs

Figure 6 represents the relaxation rate by cumulative perfusion of ACh $\left(10^{-6} \mathrm{M}\right)$ in the presence of NE in the mesenteric vasculature of SHRSP fed a DHA-Euglena diet or treated with antihypertensive drugs starting from the age of 5 weeks. The relaxation rate at 13 weeks of age was $81 \%$ in the DHA-Euglena diet group, which was significantly higher $(p<0.01)$ than $61 \pm 9 \%$ of the control group. This value was similar to the relaxation rate $(83 \%)$ of WKY at the same age. In the antihypertensive-treated groups, on the other hand, the relaxation rate was $82 \%$ in the captopril-treated group, which was almost same as in the DHA-Euglena diet group. In the hydralazine-treated group, however, it was $65 \%$. The relaxation rate in the control group was lower at 18 weeks of age than at 13 weeks of age showing that deterioration of endothelium-dependent relaxation was promoted. In the DHA-Euglena diet group and the captopril-treated group, the relaxation rates were similar at 13 and 18 weeks of age.

\section{DISCUSSION}

Vascular endothelial cells produce and release not only EDRF but also endothelium-derived contracting factor (EDCF) as the result of various stimulations, and they contribute to regulation of the blood pressure. In SHR and SHRSP, it has been reported that the endothelium-dependent relaxation response is weaker as compared to that in WKY, in various vascular beds (5-12). Sunano et al. (9, $11,12)$ reported that impairment of the aorta by endothelium-dependent relaxation could be prevented by arresting blood pressure elevation through the administration of antihypertensive drugs to SHRSP prior to the elevation of blood pressure (10). Even after hypertension was established, lowering the blood pressure with anti- 
hypertensive drugs was reported to restore endothelium-dependent relaxation, and hence it is believed that this impairment is not determined genetically but is a secondary change due to persistance against hypertension. Similar changes were observed in the secondary hypertensive vessels of Dahl salt-sensitive rats (17-19) and renal hypertensive rats $(20,21)$. However, when blood pressure returned to the normal level, endothelium-dependent relaxation recovered, suggesting that an abnormality in endothelial cell functions was caused by the persistence of hypertension. The authors, using SHRSP, studied the prevention and therapy of cerebral stroke by nutritional approach using Euglena as the protein source. When an Euglena diet was administered to SHRSP before the onset of hypertension, it prevented stroke and prolonged the life-span although the suppressive effect on blood pressure elevation was not significant (14). In SHRSP fed this diet, suppression of the decrease in elastin, an elastic protein composing the vascular wall, and suppression of hypertrophy through lowering the ACE activity of the vascular wall $(14,22)$ were noted. Hence, Euglena is believed to have some effect on the architecture of the vascular wall.

Recently, DHA-Euglena accumulating DHA which has been noted to have various physiological functions has been developed (16). In SHRSP fed a diet containing DHA-Euglena as the protein source, the elevation of blood pressure was suppressed, and the incidence of cerebral stroke lesion was lowered as compared to Euglena by ordinary cultivation without added DHA (15). In this study, the effects of DHA-Euglena on vascular accidents occurring along with the progress of hypertension in SHRSP were investigated from the aspect of endothelial function. The experiment was conducted using the mesenteric artery of the resistance vessel which is believed to reflect the pathology of hypertension. Blood pressure elevation in the DHA-Euglena diet group was somewhat suppressed, and endotheliumdependent relaxation was clearly higher as compared to the control group; the relaxation rate was similar to that of normotensive WKY, and it was shown that the impairment of vascular endothelium was slight in the SHRSP of the DHA-Euglena diet group. We have already noted (14) in the electron microscopic observation of endothelial cells, elastic fibers and smooth muscle cells of the mesenteric artery of SHRSP fed a Euglena diet, that impairment of the arterial wall is slight in the Euglena diet group as compared to the control diet group. The results of the present experiment support the finding physiologically. On the other hand, in the hydralazine-treated group set up to compare the effect of DHA-Euglena, the hypotensive action was stronger than in the DHA-Euglena diet group, but the endothelium-dependent relaxation was attenuated. In the captopril-treated group, a marked hypotensive action was noted, and the reduction of endotheliumdependent relaxation was suppressed. The relaxation rate, however, was similar to that in the DHA-Euglena diet group, and the improvement of endothelial function was not related to lowering the blood pressure. In the aorta of SHR and SHRSP, in the younger stage before the onset of hypertension, there is no histological difference in the tunica intima from the aorta of WKY, but after the onset of 
hypertension, abnormality in endothelial cells is observed (7,23-25). Such changes in the endothelium or tunica intima can be prevented by early treatment with antihypertensive drugs. It is also known that treatment with antihypertensive drugs has a preventive effect even after the onset of hypertension $(26,27)$. The authors reported $(14,28)$ results suggesting that the progression of vascular disorder can be blocked by nutritional improvement even if hypotensive action is not observed. Recently, the authors reported that the ACE activity of the aorta was lowered in SHRSP fed a Euglena diet from the advanced stage of hypertension (22). From this diet, lower blood pressure was not recognized. But similar to ACE inhibitor captopril, hypertrophy of the vascular wall was suppressed, pointing out that the alleviation of vascular resistance by lowering blood pressure is not the only important aspect. Similar results were noted in experiments using DHA-Euglena diet (15) and fish meal as protein sources (29). Okamoto et al. (30), using malignant SHRSP (M-SHRSP), studied the effects of a fish meal diet and antihypertensive drug administration on cerebrovascular lesions, and found that a vascular protective action was exhibited by treatment with ACE inhibitor even if the blood pressure was not lowered in M-SHRSP. The reduction of endotheliumdependent relaxation of blood vessels in SHR and SHRSP is advanced by the persistence of hypertension, but the endothelial function can be normalized by lowering the blood pressure through treatment with antihypertensive drugs. Furthermore, the improvement of nutritional factors can prevent functional changes in the endothelium without markedly lowering the blood pressure. These results hence suggest that the endothelial functions may be protected by appropriate consideration of the nutrients to be taken from an early age if the subject has the disposition of hypertension. Henceforth, prevention of hypertension or stroke should be viewed from this viewpoint.

Concerning the suppressive action of reducing endothelium-dependent relaxation in SHRSP observed in this study, it is not known whether this is due to DHA or other components in the Euglena diet such as protein. At the present time, the authors are studying the effects of the $n-3$ series fatty acids, namely, $\alpha$-linolenic acid, eicosapentaenoic acid and DHA, on the impairment of endotheliumdependent relaxation reaction in the blood vessels of SHRSP. It is expected that the mechanism of action of these highly unsaturated fatty acids will be disclosed from these results.

\section{REFERENCES}

1) Furchgott RF, Zawadzki JV. 1980. The obligatory role of endothelial cells in the relaxation of arterial smooth muscle by acetylcholine. Nature 288: 373-376.

2) Furchgott RF. 1983. Role of endothelium in responses of vascular smooth muscle. Circ Res 53: 557-573.

3) Furchgott RF. 1984. The role of endothelium in the response of vascular smooth muscle to drugs. Ann Rev Pharmacol Toxicol 24: 175-197. 
4) Ignarro LJ. 1989. Endothelium-derived nitric oxide; actions and properties. FASEB J 3: 31-36.

5) Watt PAC, Thurston H. 1989. Endothelium-dependent relaxation in resistance vessel from the spontaneously hypertensive rats. $J$ Hypertens 7: 661-666.

6) Lüscher TF, Diederich D, Weber E, Vanhoutte PM, Buhler FR. 1988. Endotheliumdependent responses in carotid and renal arteries of normotensive and hypertensive rats. Hypertension 11: 573-578.

7) Sugimoto T, Tobian L, Ganguli MC. 1988. High potassium diets protect against dysfunction of endothelial cells in stroke-prone spontaneously hypertensive rats. $\mathrm{Hy}$ pertension 11: 579-585.

8) Tesfamariam B, Halpern W. 1988. Endothelium-dependent and endothelium-independent vasodilation in resistance artery from hypertensive rats. Hypertension 11: 440444.

9) Sunano S, Osugi S, Shimamura K. 1989. Blood pressure and impairment of endothelium-dependent relaxation in spontaneously hypertensive rats. Experientia 45: 705-707.

10) Diederich D, Yang Z, Buhler FR, Lüscher T. 1990. Impaired endothelium-dependent relaxations in hypertensive resistant arteries involve cycloxygenase pathway. Am J Physiol 258: H445-H451.

11) Shimamura K, Osugi S, Sunano S. 1991. Impairment and protection of endotheliumdependent relaxation in aorta of various strains of spontaneously hypertensive rats. $J$ Cardiovasc Pharmacol 17 (Suppl 3): S133-S135.

12) Sunano S, Osugi S, Kaneko K, Yamamoto K, Shimamura K. 1992. Effects of chronic treatment with SQ29852 on spontaneous smooth muscle tone and endotheliumdependent relaxation in aorta of stroke-prone spontaneously hypertensive rats. $J$ Cardiovasc Pharmacol 19: 602-609.

13) Nigro D, Fortes ZB, Carvalho MHC, Scivoletto R. 1989. Chronic but not acute treatment with hydralazine reverses the decreased endothelium-dependent responses in spontaneously hypertensive rats. Clin Exp Hyper Theory Practice A11(A): 573-586.

14) Murakami T, Okamoto K, Kitaoka S, Iizuka Y. 1988. Effect of Euglena cells on blood pressure, cerebral and peripheral vascular changes and life-span in stroke-prone spontaneously hypertensive rats. Nippon Eiyo Shokuryo Gakkaishi (J Jpn Soc Nutr Food Sci) 41: 115-125.

15) Murakami T, Ogawa H, Hayashi M, Yoshizumi H. 1995. Effect of Euglena (Euglena gracilis Z) with enriched docosahexaenoic acid on blood pressure, stroke lesion and life-span in stroke-prone spontaneously hypertensive rats. Nippon Eiyo Shokuryo Gakkaishi (J Jpn Soc Nutr Food Sci) 48: 209-215.

16) Hayashi M, Toda K, Kitaoka S. 1993. Enriching Euglena with unsaturated fatty acids. Biosci Biotech Biochem 57: 352-353.

17) Raij L, Lüscher TF, Vanhoutte PM. 1988. High potassium diet augments endothelium-dependent relaxation in Dahl rats. Hypertension 12: 562-567.

18) Lüscher TF, Vanhoutte PM, Raij L. 1987. Antihypertensive treatment normalizes decreased endothelium-dependent relaxation in rats with salt-induced hypertension. Hypertension 9 (Suppl III): 193-197.

19) Lüscher TF, Raij L, Vanhoutte PM. 1987. Endothelium-dependent vascular responses in normotensive and hypertensive Dahl rats. Hypertension 9: 157-163. 
20) Lockette W, Otsuka Y, Carretero O. 1986. The loss of endothelium-dependent vascular relaxation in hypertension. Hypertension 8 (Suppl II): II-61-II-66.

21) Van de Voorde J, Luesen I. 1986. Endothelium-dependent and independent relaxation of aortic rings from hypertensive rats. Am J Physiol 250: H711-H717.

22) Murakami T, Hayashi M, Yoshizumi H. 1995. Lowering of the vascular tissue angiotensin I-converting enzyme activity and suppression of the hypertrophy of vascular wall in stroke-prone spontaneously hypertensive rats fed Euglena (Euglena gracilis Z) diet. Nippon Eiyo Shokuryo Gakkaishi (J Jpn Soc Nutr Food Sci) 48: 203208.

23) Lee RMKW. 1985. Vascular changes at the prehypertensive phase in the mesenteric arteries from spontaneous hypertensive rats. Blood Vessels 22: 105-126.

24) Lee RMKW, McKenzie R, Roy M. 1988. Ultrastructure and morphometric measurements of mesenteric arteries from newborn spontaneous hypertensive rats. Blood Vessels 25: 105-114.

25) Limas C, Westrum B, Limas CJ. 1980. The evolution of vascular changes in the spontaneous hypertensive rats. Am J Pathol 98: 357-384.

26) Limas C, Westrum B, Limas CJ. 1983. Effect of antihypertensive therapy on the vascular changes of spontaneous hypertensive rats. Am J Pathol 111: 380-393.

27) Haudenschild CC, Chobanian AV. 1984. Blood pressure lowering diminishes agerelated changes in the rat aortic intima. Hypertension 6 (Suppl I): I-62-I-68.

28) Murakami T, Tsuji A, Yamamoto K, Okamoto K. 1992. Effect of a fish meal diet initiated at the hypertensive stage on the development of cerebrovascular lesions in SHRSP. Nippon Eiyo Shokuryo Gakkaishi (J Jpn Soc Nutr Food Sci) 45: 129-137.

29) Murakami T, Soga M, Mitsunaga T, Yoshizumi H, Ito H. 1994. The vascular tissue angiotensin I-converting enzyme activity and aortic elastin content in stroke-prone spontaneously hypertensive rats fed fish diet. Clin Exp Pharmacol Physiol 21: 453-461.

30) Okamoto K, Ohta Y, Chikugo T, Shiokawa H, Morita N. 1991. Chronic treatment with captopril, SQ29, 852, hydralazine and a 33\% fish meal diet in malignant stroke-prone spontaneously hypertensive rats. J Hypertens 9: 1105-1111. 